\title{
CORRIGENDUM
}

\section{Immunoglobulin heavy/light chain ratios improve paraprotein detection and monitoring, identify residual disease and correlate with survival in multiple myeloma patients}

H Ludwig, D Milosavljevic, N Zojer, JM Faint, AR Bradwell, W Hübl and SJ Harding

Leukemia (2013) 27, 996; doi:10.1038/leu.2013.25

Correction to: Leukemia (2013) 27, 213-219; doi:10.1038/ leu.2012.197

Since the publication of this article, the authors have noticed an error within Figure 1, namely that the data for the $\lg$ and $\lg A$ patients have been linked to the wrong panel.
Figure 1a should have displayed the data for the lgG patients, and Figure $1 \mathrm{~b}$ should have displayed the data for the $\lg \mathrm{A}$ patients.

The correct figure is shown here.

The authors would like to apologise for any inconvenience this may have caused.
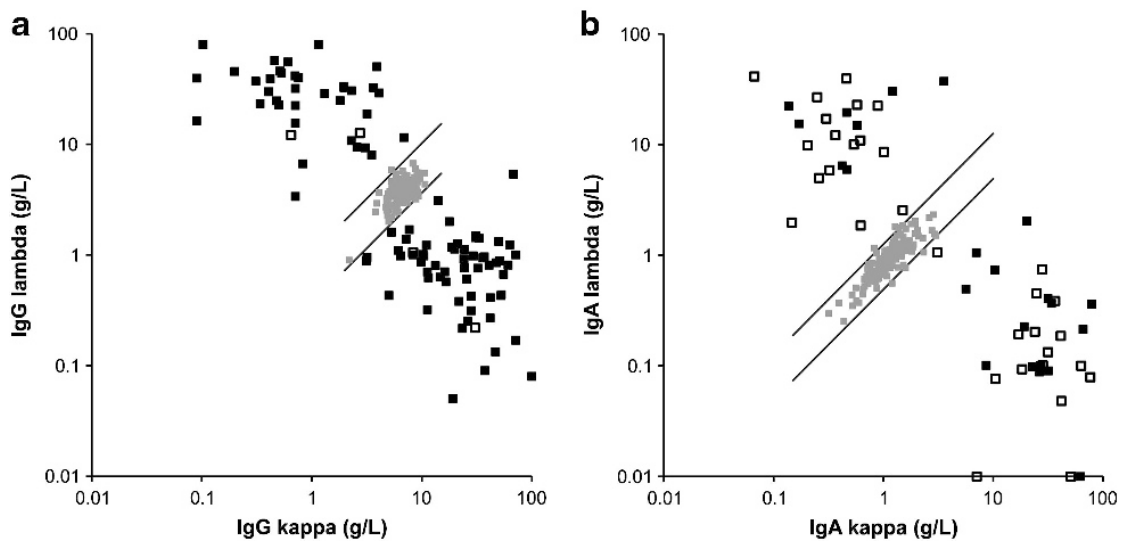

Figure 1. Scatter graph of the HLC values. All individual values of the 100 patients with IgG (a) and of the 56 patients with IgA M-lg (b) were outside the normal range. The solid squares denote patients with quantifiable M-lgs by SPEP, whereas open squares denote patients with anodal migration of their M-Igs, which made accurate quantification impossible. 